\title{
Examining the Impact of Excessive Daytime Sleepiness on Utility Scores in Patients with Obstructive Sleep Apnoea and/or Narcolepsy in Five European Countries
}

\section{Janelle Cambron-Mellott}

Cerner Enviza

Sam Mettam ( Sam.Mettam@jazzpharma.com )

Jaz Pharmaceuticals https://orcid.org/0000-0003-3656-4089

Vicky W. Li

Cerner Enviza

John C. Rowland

Cerner Enviza

JeanPierre Coaquira Castro

Jazz Pharmaceuticals

\section{Research}

Keywords: health states utilities, excessive daytime sleepiness, obstructive sleep apnoea, narcolepsy, Epworth Sleepiness Scale

Posted Date: December 9th, 2021

DOI: https://doi.org/10.21203/rs.3.rs-1145989/v1

License: (c) (i) This work is licensed under a Creative Commons Attribution 4.0 International License.

Read Full License 


\section{Abstract}

Background: Excessive daytime sleepiness (EDS) is a cardinal symptom of narcolepsy and affects many patients with obstructive sleep apnoea (OSA). EDS is associated with reduced quality of life, increased accident risk, and poor workplace performance. Given the impact of EDS, the ability to predict healthrelated utility from sleepiness is valuable for examining the cost effectiveness of novel treatments. The aim of this study was to examine the association between EDS and EQ-5D in patients with OSA and/or narcolepsy by modelling EQ-5D utility scores from Epworth Sleepiness Scale (ESS) scores.

Methods: Data were obtained from the Europe 2016/2017 National Health and Wellness Survey, an online, general population survey, designed to represent the age and gender composition of each country's adult population. Analyses included 2,348 patients self-reporting symptomatic and diagnosed OSA $(n=2,277)$, narcolepsy $(n=48)$, or both $(n=23)$. Multivariable models were used to examine ESS as a predictor of EQ-5D utility while adjusting for covariates of interest. Results were validated following the National Institute for Health and Care Excellence Decision Support Unit guidelines for predictive modeling.

Results: Utility decreased as EDS severity increased (no EDS: $0.711 \pm 0.251$, mild: $0.685 \pm 0.261$, moderate: $0.643 \pm 0.268$, severe: $0.559 \pm 0.323$ ). Whereas participants with only OSA or only narcolepsy did not differ in utility, those with both conditions had lower scores $(0.685 \pm 0.266$ and $0.627 \pm 0.325$ vs. $0.439 \pm 0.340$, respectively). Piecewise linear regression identified a single breakpoint at ESS score of 11.29. In the final model, for each point increase in ESS score, the corresponding decrease in EQ-5D utility was larger among patients with ESS scores $\geq 12$ compared to patients with ESS scores $\leq 11$ (model slopes: -0.0131 vs. -0.0026 , respectively). Findings from the validation sample confirmed these results.

Conclusions: This study demonstrates the impact of sleepiness on quality of life (QoL) and its negative impact irrespective of sleep condition (OSA or narcolepsy). The breakpoint identified is relatively consistent with the established ESS cutoff score $\geq 11$, which demarcates pathological sleepiness. Furthermore, as EDS severity worsens (increases) on the ESS, the impact on QoL is greater.

\section{Background}

Excessive daytime sleepiness (EDS) is the primary concern for many patients with sleep disorders and is characterized by the inability to stay awake, alert, and optimally functional throughout the day.[1] EDS has been estimated to affect between $2.5 \%$ and $26.1 \%$ of the general population, varying depending on the definition applied and method of assessment.[2]

The most common causes of EDS are insufficient sleep and poor sleep quality.[3] Sleep continuity is a crucial factor in determining sleep quality, with sleep breathing disorders such as sleep apnoea representing a common cause of sleep disruption. Many neurological and psychiatric disorders are associated with EDS.[3, 4] 
In narcolepsy, a chronic disorder characterized by the dysregulation of the sleep/wake cycle, EDS is the cardinal symptom $[5,6]$ and is generally present in all patients. [5-8] Narcolepsy is characterized by recurrent, uncontrollable brief episodes of sleep and lapses in consciousness; other symptoms of narcolepsy include hypnagogic and hypnopompic hallucinations, cataplexy, sleep paralysis, and disrupted nocturnal sleep.[3] The prevalence of narcolepsy in the general population is relatively low, estimated to be around 0.04\%.[2]

EDS is also a prominent symptom in obstructive sleep apnoea (OSA), which is characterized by frequent partial arousals that occur throughout sleep as a result of recurrent episodes of partial or complete collapse of the upper airway.[9] OSA has a high prevalence in the general population; a 2019 study estimates OSA affects 936 million adults aged 30 to 69 years globally, or approximately $12 \%$ of the world's population.[10] This study extrapolated country-specific prevalence rates, including five European countries (France, Germany, Italy, Spain, United Kingdom [UK]), with prevalence of moderate to severe OSA estimated at $21.4 \%$, ranging from $4.8 \%$ in the UK to $36.3 \%$ in France.[10] While many studies examining the prevalence of OSA in Europe have shown varying rates between countries, one consistent finding is that the prevalence of OSA is higher in men than women.[11-16] The prevalence of OSA associated with EDS is approximately 3 to $7 \%$ for men and 2 to $5 \%$ for women in the general population, [9] and it has been found that residual EDS remains in up to $13 \%$ of patients even after continuous positive airway pressure (CPAP) treatment.[17]

EDS is a significant public health problem with serious economic consequences. EDS is associated with poor health-related quality of life (HRQoL), poor performance in the workplace and increased risk of accidents.[18] Narcolepsy is associated with significant impact on HRQoL,[19] with EDS emerging as a strong predictor of poor HRQoL in patients with narcolepsy.[20-23] Furthermore, treatment with stimulants or wakefulness-promoting agents at dosages high enough to alleviate EDS in patients with narcolepsy often leads to adverse effects.[3]

There is also increasing evidence that higher levels of EDS in patients with OSA account for an increased burden of disease. This includes an increased risk of cardiovascular disease,[24] depression,[25] and diabetes,[26] greater deficits in work productivity,[27] increased health-care utilization,[28] and worse HRQoL.[29, 30]

EDS may be assessed by the Epworth Sleepiness Scale (ESS), an 8-item patient-reported outcome scale that scores respondents on how likely they are to doze off during certain daily activities (e.g., sitting and reading, watching TV, etc.).[31] Given the impact of EDS, the ability to predict health-related utility from ESS scores is valuable for examining the cost effectiveness of treatments for EDS. Indeed, while developing the technology appraisal guidance for CPAP machines, the National Institute for Health and Clinical Excellence (NICE; the UK's health technology assessment agency) assessment group identified three studies that examined ESS score and SF-36 and/or EQ-5D data, and using this data, used a linear regression model to predict utility from ESS scores.[32] This led to the development of a mapping algorithm to convert ESS scores into utility scores in the 2008 NICE CPAP appraisal; the cost 
effectiveness of CPAP machines was then examined by applying the mapping algorithm to data on mean difference in ESS scores between individuals treated with CPAP machines compared to those treated with placebo or compared to those treated with dental devices.[32] However, the mapping algorithm based on EQ-5D was generated based on data from only 94 patients with OSA.[33]

The current study aimed to expand on the previous research undertaken by NICE by including data from a larger number of patients, including patients with OSA and/or narcolepsy, and examining alternative models to simple linear regression to explain the association between EDS and EQ5D utility scores. Therefore, the objective of the current study was to examine the association between EDS and HRQoL in patients with OSA and/or narcolepsy to predict EQ-5D utility scores from ESS scores.

\section{Methods}

\section{Data Source and Procedures}

This retrospective, cross-sectional study used data from 5 European countries (France, Germany, the UK, Italy, and Spain) from the 2016 and 2017 National Health and Wellness Survey (NHWS), a selfadministered, internet-based questionnaire completed by adults (aged 18 years or older). The NHWS is designed to reflect the general population of each country surveyed using quota sampling based on age and sex for each country.

Potential respondents were identified primarily through participation in opt-in online survey panels. In 2016, online panel recruitment in Germany and Italy was supplemented by computer-assisted web interviews, in which respondents 65 years of age or older were recruited on the telephone and have the choice to complete the interview by phone. This was done to further ensure representativeness, particularly in the population $65+$ years old.

Respondents were included if they self-reported having been clinically diagnosed with OSA and/or narcolepsy, self-reported experiencing OSA and/or narcolepsy in the past 12 months, and completed the ESS. Importantly, although the NHWS does not ask patients to specify their type of sleep apnoea (i.e., obstructive, central), this study made the analytic decision to accept sleep apnoea as adequately capturing and representing OSA based on the significantly higher prevalence of OSA compared to central sleep apnoea, with recent analysis of baseline data from a large community-based cohort study (i.e. the Sleep Heart Health Study) calculating a prevalence of $47.6 \%$ and $0.9 \%$, respectively, among adults aged 40 years and over.[34] This same approach was used by Stepnowsky et al.[35]

In 2017, all respondents who reported experiencing OSA and/or narcolepsy in the past 12 months completed the ESS module, whereas in 2016 only a random subset of patients eligible to answer module questions did so. In cases where respondents participated in multiple years, the most recent data were analyzed. 
The protocol and questionnaire for the 2016 and 2017 NHWS were reviewed and granted exemption by the Pearl Institutional Review Board (IRB) as it was determined this study met the exemption requirements under 45CFR46.101(b)(2). All respondents provided informed consent.

\section{Measures}

\section{Predictor Variable}

For quantification of EDS status, the predictor variable for this study was the ESS score, ranging from 024 (higher scores indicating worse daytime sleepiness).

The ESS was analyzed as a continuous score and as a categorical measure of EDS status, using two cutoffs sets. The first set used the following thresholds to delineate ESS scores: $\leq 10$ 'no EDS', 11-12 'mild EDS', 13-15 'moderate EDS' and >16 'severe EDS'. The threshold delineating non-pathological from pathological levels of sleepiness $(\geq 11)$ was developed in an Australian population,[36] and the thresholds delineating the degree of EDS were empirically developed based on data reported by patients with narcolepsy.[37] These cutoffs are widely used in the United States (US) and abroad (except in the UK) and will be referred to in this study as US/Rest of World (RoW) cutoffs.[37, 38] The second set utilized thresholds found on the NICE Clinical Knowledge Summaries site.[39] They are referred to here as UK cutoffs with an ESS score of $\leq 10$ indicating 'no EDS', 11-14 'mild EDS', 15-18 'moderate EDS', and 1924 'severe EDS'.

\section{Covariates and Other Variables of Interest}

Respondents were categorized according to their sleep disorder: 'OSA without narcolepsy', 'narcolepsy without OSA', or both 'OSA and narcolepsy'. Additionally, information was collected on a variety of sociodemographic and health characteristics including age, sex, country, marital status, education, labor force participation, employment status, annual household income, body mass index (BMI) category, smoking status, alcohol use, exercise activity, and Charlson Comorbidity Index (CCl) score.

\section{Outcome Variable}

The outcome variable for this study was the EQ-5D utility score. The EQ-5D utility score is derived from responses to the EQ-5D-5L, a widely-used, generic survey instrument which measures health status and consists of five dimensions: mobility, self-care, usual activities, pain/discomfort, and anxiety/depression; with 5-point rating scales for each dimension.[40]

Each health state can be assigned a summary utility score based on representative preference weights for the health state. Health state utility scores generally range from less than 0 (where 0 is the score of a health state equivalent to dead; negative values representing health states worse than dead) to 1 (the score equivalent to full health), with higher scores indicating higher utility.[22] These utility scores were calculated by mapping the five-level descriptive system onto the three-level valuation set using the mapping function developed by van Hout et al.[41] Health states were mapped using their own countryspecific value set. 


\section{Statistical Analysis}

Descriptive analyses, including means and standard deviations (SD) for continuous variables and counts and percentages for categorical variables, were conducted to examine demographic and health variables by OSA/narcolepsy status. Descriptive statistics, using means and SDs, were also used to examine EQ-5D utility scores by OSA/narcolepsy status and by EDS status using the US/RoW cutoffs.

Multivariable models were used to develop an equation to predict EQ-5D utility scores from ESS scores, while adjusting for variables of interest. The included covariates were OSA/narcolepsy status, age, $\mathrm{CCl}$, sex, marital status, income, BMI, smoking status, alcohol use, and exercise.

Four models were initially run; three models utilized generalized linear models (GLMs), specifying normal distribution and identify link function, to examine EQ-5D utility scores by continuous ESS scores (model (a)), and categorical EDS status (no EDS [reference], mild EDS, moderate EDS, and severe EDS) using US/RoW cutoffs (model (b)) and using UK cutoffs (model (c)). The fourth model utilized piecewise linear regression to identify whether there was a breakpoint in the linear relationship between ESS scores and EQ-5D utility scores (model $(d)$ ).

After reviewing results from these four models, a linear spline regression (model (e)) was run to improve interpretability. Specifically, the explanatory variable was portioned into intervals reflecting the segments identified in (d), utilizing discrete ESS score cutoffs, and a separate line segment was fit to each interval. An interaction term was included in the final model to examine whether ESS scores and OSA/narcolepsy status interacted to predict EQ-5D utility scores.

Model fit was assessed in terms of deviance, Akaike information criterion (AIC), and Bayesian information criterion (BIC). P-values were reported for continuous and categorical ESS scores, depending on the model. Due to no adjustments for multiplicity, the $P$-values presented are nominal.

The final model equation was validated following the NICE Decision Support Unit guidelines for predictive modeling.[32] This included splitting the full sample into estimation and validation samples using a 70/30 split for additional analyses, running bivariate comparisons between the estimation and validation samples across all covariates/outcomes in the model, running the final model on the estimation and validation samples and assessing model fit through root mean square error (RMSE), assessing bias in prediction by calculating RMSE by quartiles of EQ-5D and plotting observed vs. predicted values, and running a piecewise linear regression on the estimation sample to determine if a breakpoint in ESS score existed and then compare to the breakpoint identified in the full sample.

\section{Results}

A total of 2,348 respondents self-reported both symptomatic (experienced in the last 12 months) and physician-diagnosed 'OSA without narcolepsy' ( $n=2,277)$, 'narcolepsy without OSA' $(n=48)$, or both 'OSA and narcolepsy' $(n=23)$. Participants with OSA without narcolepsy were on average older (mean \pm SD: 
$59.3 \pm 12.5$ years) than participants with OSA and narcolepsy ( $53.3 \pm 14.1$ years) and participants with narcolepsy without OSA (49.0 \pm 17.8 years). The majority of participants in both OSA groups were male (70.5\% of 'OSA without narcolepsy' participants and $69.6 \%$ of 'OSA and narcolepsy' participants), while just under half of the 'narcolepsy without OSA' participants were male (47.9\%). Participants with narcolepsy reported higher proportions of severe EDS (35.4\% of participants with narcolepsy without OSA and $39.1 \%$ of participants with OSA and narcolepsy) than participants with OSA without narcolepsy (11.9\%). Other participant characteristics are presented in Table 1. 
Table 1

Participant characteristics by OSA/narcolepsy status

\begin{tabular}{|c|c|c|c|}
\hline & $\begin{array}{l}\text { OSA without } \\
\text { narcolepsy }\end{array}$ & $\begin{array}{l}\text { Narcolepsy without } \\
\text { OSA }\end{array}$ & $\begin{array}{l}\text { OSA and } \\
\text { narcolepsy }\end{array}$ \\
\hline Characteristic & $(\mathrm{N}=2,277)$ & $(\mathrm{N}=48)$ & $(\mathrm{N}=23)$ \\
\hline Age, years, mean (SD) & $59.3(12.5)$ & $49.0(17.8)$ & $53.3(14.1)$ \\
\hline Male, n (\%) & $1,606(70.5)$ & $23(47.9)$ & $16(69.6)$ \\
\hline \multicolumn{4}{|l|}{ Country, n (\%) } \\
\hline France & $707(31.0)$ & $16(33.3)$ & $6(26.1)$ \\
\hline Germany & $689(30.3)$ & $13(27.1)$ & $6(26.1)$ \\
\hline UK & $334(14.7)$ & $7(14.6)$ & $5(21.7)$ \\
\hline Italy & $236(10.4)$ & $7(14.6)$ & $5(21.7)$ \\
\hline Spain & $311(13.7)$ & $5(10.4)$ & $1(4.3)$ \\
\hline Married/living with partner, $\mathrm{n}(\%)$ & $1,591(69.9)$ & $24(50.0)$ & $12(52.2)$ \\
\hline University degree, n (\%) & $804(35.3)$ & $20(41.7)$ & $8(34.8)$ \\
\hline \multicolumn{4}{|l|}{ Annual household income, $\mathrm{n}(\%)$} \\
\hline Low $(<€ / £ 20,000)$ & $587(25.8)$ & $17(35.4)$ & $8(34.8)$ \\
\hline Medium ( $€ / £ 20,000$ to $€ / £ 39,999)$ & $903(39.7)$ & $22(45.8)$ & $8(34.8)$ \\
\hline High ( $€ / £ 40,000$ or more) & $622(27.3)$ & $7(14.6)$ & $6(26.1)$ \\
\hline CCI mean (SD) & $0.6(1.2)$ & $1.3(2.9)$ & $2.0(2.6)$ \\
\hline $\begin{array}{l}\text { Overweight/obese (BMl, } \geq 25 \\
\left.\mathrm{~kg} / \mathrm{m}^{2}\right), \mathrm{n}(\%)\end{array}$ & $1,870(82.1)$ & $23(47.9)$ & $17(73.9)$ \\
\hline \multicolumn{4}{|l|}{ Smoking status, $\mathrm{n}(\%)$} \\
\hline Never smoker & $711(31.2)$ & $12(25.0)$ & $4(17.4)$ \\
\hline Former smoker & $1,032(45.3)$ & $20(41.7)$ & $10(43.5)$ \\
\hline
\end{tabular}

CCl: Charlson Comorbidity Index; EDS: excessive daytime sleepiness; N: number of participants; $n$ : number of participants with observations; OSA: obstructive sleep apnoea; SD: standard deviation.

\section{Additional File 1}

File Name: Additional File 1

File Format: PDF

Title and description of data: 


\begin{tabular}{|llll|}
\hline & $\begin{array}{l}\text { OSA without } \\
\text { narcolepsy }\end{array}$ & $\begin{array}{l}\text { Narcolepsy without } \\
\text { OSA }\end{array}$ & $\begin{array}{l}\text { OSA and } \\
\text { narcolepsy }\end{array}$ \\
\hline Current smoker & $534(23.5)$ & $16(33.3)$ & $9(39.1)$ \\
\hline Alcohol use, yes, $n(\%)$ & $1,747(76.7)$ & $36(75.0)$ & $15(65.2)$ \\
\hline $\begin{array}{l}\text { Exercised } \geq 1 \text { time in past month, } n \\
\text { (\%) }\end{array}$ & $1,147(50.4)$ & $24(50.0)$ & $11(47.8)$ \\
\hline EDS status, $n$ (\%) & $1,530(67.2)$ & $18(37.5)$ & $9(39.1)$ \\
\hline No EDS (ESS, 0-10) & $221(9.7)$ & $7(14.6)$ & $2(8.7)$ \\
\hline Mild EDS (ESS, 11-12) & $256(11.2)$ & $6(12.5)$ & $3(13.0)$ \\
\hline Moderate EDS (ESS, 13-15) & $270(11.9)$ & $17(35.4)$ & $9(39.1)$ \\
\hline Severe EDS (ESS, 16-24) & & & \\
\hline $\begin{array}{l}\text { CCl: } \text { Charlson Comorbidity Index; EDS: excessive daytime sleepiness; N: number of participants; } \mathrm{n}: \\
\text { number of participants with observations; OSA: obstructive sleep apnoea; SD: standard deviation. }\end{array}$ & \\
\hline Additional File 1 & & & \\
\hline File Name: Additional File 1 & & \\
\hline File Format: PDF & & \\
\hline Title and description of data: & & \\
\hline
\end{tabular}

Participants with only OSA or only narcolepsy did not differ in EQ5D utility scores, but those with both conditions had lower scores ( $0.685 \pm 0.266$ vs. $0.627 \pm 0.325$ vs. $0.439 \pm 0.340$, respectively). When examining EQ-5D utility scores by EDS status, utility decreased as EDS severity increased, from $0.711 \pm 0.251$ for participants with no EDS to $0.559 \pm 0.323$ for participants with severe EDS (Table 2).

Table 2

EQ-5D utility scores by EDS status

\begin{tabular}{|c|c|c|c|c|}
\hline & $\begin{array}{l}\text { No EDS } \\
\text { (ESS, 0-10) }\end{array}$ & $\begin{array}{l}\text { Mild EDS } \\
\text { (ESS, 11- } \\
12)\end{array}$ & $\begin{array}{l}\text { Moderate EDS (ESS, 13- } \\
\text { 15) }\end{array}$ & $\begin{array}{l}\text { Severe EDS } \\
\text { (ESS, 16- } \\
24)\end{array}$ \\
\hline & $(\mathrm{N}=1,557)$ & $(\mathrm{N}=230)$ & $(\mathrm{N}=265)$ & $(\mathrm{N}=296)$ \\
\hline $\begin{array}{l}\text { EQ-5D utility scores, mean } \\
\text { (SD) }\end{array}$ & $\begin{array}{l}0.711 \\
(0.251)\end{array}$ & $\begin{array}{l}0.685 \\
(0.261)\end{array}$ & $0.643(0.268)$ & $\begin{array}{l}0.559 \\
(0.323)\end{array}$ \\
\hline
\end{tabular}

Models were run in accordance to the steps outlined in the methods. Parameter estimates for the ESS scores of all models are presented in Table 3. Parameter estimates for all variables are available in 
Supplementary Table S1(see Additional File 1). Model fit is presented in Table 4.

Table 3

Parameter estimates for the ESS scores of the models run

\begin{tabular}{|llll|}
\hline Model & Estimate & SE & $P$ \\
\hline (a) GLM - ESS score as a continuous variable & -0.0068 & 0.0009 & $<.001$ \\
\hline (b) GLM - US/RoW cutoffs (reference 0-10) & & & \\
\hline Mild EDS (ESS, 11-12) & -0.0134 & 0.0174 & .44 \\
\hline Moderate EDS (ESS, 13-15) & -0.0505 & 0.0165 & .002 \\
\hline Severe EDS (ESS, 16-24) & -0.1132 & 0.0159 & $<.001$ \\
\hline (c) GLM - UK cutoffs (reference 0-10) & & & \\
\hline Mild EDS (ESS, 11-14) & -0.0268 & 0.0138 & .05 \\
\hline Moderate EDS (ESS, 15-18) & -0.0789 & 0.0167 & $<.001$ \\
\hline Severe EDS (ESS, 19-24) & -0.1513 & 0.0236 & $<.001$ \\
\hline (d) Piecewise linear with breakpoint at 11.29 & & & \\
\hline ESS Slope 1 (ESS, <11.29) & -0.0028 & 0.0018 & .13 \\
\hline ESS Slope 2 (ESS, >11.29) & -0.0134 & 0.0031 & $<.001$ \\
\hline (e) Linear spline with breakpoint at 11 & & & .11 \\
\hline ESS, 0-11 & -0.0026 & 0.0016 & $<.001$ \\
\hline ESS, 12-24 & -0.0131 & 0.0022 & \\
\hline
\end{tabular}

Note: $P$-values for models a-c were calculated using Wald chi-square tests. $P$-values for models d-e were calculated using t-tests. Due to no adjustments for multiplicity, $P$-values presented are nominal.

ESS: Epworth Sleepiness Scale; GLM: generalized linear model; RoW: rest of world, SE: standard error; UK: United Kingdom; US: United States. 
Table 4

Fit indices for models run

\begin{tabular}{|c|c|c|c|c|c|}
\hline Model & Deviance & df & Deviance/df & AIC & $\mathrm{BIC}$ \\
\hline (a) GLM - ESS continuous & 142.33 & 2333 & 0.061 & 113.497 & 205.678 \\
\hline (b) GLM - US/RoW cutoffs: & 141.91 & 2325 & 0.061 & 122.601 & 260.872 \\
\hline \multicolumn{6}{|l|}{$\begin{array}{l}\text { No EDS (ESS, 0-10), mild EDS (ESS, 11- } \\
12) \text {, moderate EDS (ESS, 13-15), severe } \\
\text { EDS (ESS, 16-24) }\end{array}$} \\
\hline (c) GLM - UK cutoffs: & 141.99 & 2331 & 0.061 & 111.912 & 215.615 \\
\hline \multicolumn{6}{|l|}{$\begin{array}{l}\text { No EDS (ESS, } 0-10) \text {, mild EDS (ESS, } 11- \\
14) \text {, moderate EDS (ESS, 15-18), severe } \\
\text { EDS (ESS, 19-24) }\end{array}$} \\
\hline $\begin{array}{l}\text { (d) Piecewise linear: ESS score 0-11, ESS } \\
\text { score } 12-24\end{array}$ & 141.74 & 2331 & 0.061 & 107.752 & 211.456 \\
\hline $\begin{array}{l}\text { (e) Linear spline with breakpoint at } 11 \text { : } \\
\text { ESS score } 0-11 \text {, ESS score } 12-24\end{array}$ & 141.74 & 2332 & 0.061 & 105.809 & 203.751 \\
\hline \multicolumn{6}{|c|}{$\begin{array}{l}\text { AIC: Akaike information criterion; BIC: Bayesian information criterion; df: degrees of freedom; ESS: } \\
\text { Epworth Sleepiness Scale; GLM: generalized linear model; RoW: rest of world, UK: United Kingdom; } \\
\text { US: United States. }\end{array}$} \\
\hline \multicolumn{6}{|c|}{$\begin{array}{l}\text { The piecewise linear regression (model }(d) \text { ) identified a single breakpoint at the ESS score of } 11.29 \\
\text { with a change of }-0.0107 \text { in slope }(P=.003) \text {. As this model identified where breakpoints existed in the } \\
\text { data and had the lowest deviance, AIC, and second-lowest BIC (Table } 4) \text {, the breakpoint identified in } \\
\text { this model informed the choice of the final model. As the ESS yields discrete scores, rather than } \\
\text { estimating slopes based on the breakpoint of } 11.29 \text {, a linear spline regression model with a } \\
\text { breakpoint at ESS score of } 11 \text { (the closest applicable value of ESS to } 11.29 \text { ) was used to develop the } \\
\text { final model }(e) \text {. The slope for segment } 0-11 \text { was }-0.0026 \text { and the slope for segment } 12-24 \text { was } \\
-0.0131 \text {. This model showed best fit to the data (Table } 4 \text { ). }\end{array}$} \\
\hline
\end{tabular}

Based on the final model, the equation for estimating EQ-5D utility scores using parameter estimates was found to be:

EQ-5D utility score $=0.6080-0.0026 *$ [ESS Score 0-11] $-0.0131 *$ [ESS Score 12-24] $-0.0260 *$ [OSA without narcolepsy $]-0.1622 *[$ OSA and narcolepsy $]+0.0006 *[$ Age $]-0.0352 *[\mathrm{CCl}]-0.0579 *[$ Female $]+0.0295 *$ [Married] + 0.0496*[Medium Income] + 0.0534*[High Income] - 0.0095*[BMI above 25] + 0.0045*[Former Smoker $]-0.0028 *[$ Current Smoker $]+0.0496 *[$ Drinks alcohol $]+0.1060 *[$ Exercises $]$

Each point of increase in ESS scores between 0 to 11 is associated with a 0.0026 point of decrease in EQ$5 \mathrm{D}$ scores, whereas each point of increase in scores between 12 to 24 is associated with a 0.0131 point of decrease in EQ-5D scores. The final model was run with the interaction of sleep disorder status with ESS scores. Although an interaction occurred between the 'OSA and narcolepsy' group and ESS scores of 0-11 ( $B=0.0666, P=.006$ ), the final model excluded this interaction term due to its small sample size, as well as the complexity of the interaction, which did not significantly add to the usefulness of the model. 
The results from the validation sample supported the findings of the final linear spline regression model and are presented in Supplementary Tables S2-S4 and Supplementary Figures S1 and S2 (see Additional File 1). The values of the outcome, predictor, and covariates were similar between the estimation and validation samples (data not shown), as were the parameter estimates between the full and estimation samples (Table S2, see Additional File 1).

Due to the limited range of predicted EQ-5D index scores, the model is shown to be less predictive at the tails of the observed EQ-5D index distribution (i.e. 1st and 4th quartiles of EQ-5D, as opposed to the 2nd and 3rd quartiles), resulting in the model underpredicting for those with the lowest and highest utilities, explaining about $18 \%$ of the variance in EQ-5D overall (Table S3, see Additional File 1).

Finally, results of the piecewise linear regression model $(d)$ on the estimation sample identified a single breakpoint at ESS score 11.00 (Table S4, see Additional File 1).

\section{Discussion}

EDS manifests enormous costs in terms of health, economic and societal impact.[18] Quantifying the effect of EDS on HRQoL is crucial for assessing effective treatments, comparing treatment outcomes in clinical practice, and determining the cost effectiveness of various treatment modalities. While the ESS is one of the most commonly used subjective measures of sleep propensity in research and clinical settings, it does not provide the health-state utility measures necessary for cost-effectiveness models.

To our knowledge, this is the largest sample used to predict utility scores from ESS scores in patients with OSA and/or narcolepsy. This study successfully expands on the previous research and presents an equation for estimating EQ-5D utility scores using a linear spline regression model with a single breakpoint, based on data from 2,348 respondents that are representative of the country-specific age and sex compositions of the included countries. The relationship established in this study provides a necessary crosswalk for when ESS scores are solely available.

A single breakpoint was identified between 11 and 12 on the ESS, indicating that the slope of the regression model changes between ESS scores $\leq 11$ and $\geq 12$ ( -0.0026 vs. -0.0131 , respectively). This suggests that patients within these two segments may be differently impacted by changes in their sleepiness. Specifically, for each point increase in the ESS score, the corresponding decrease in the EQ5D utility score was larger among those with ESS scores of $\geq 12$, than for the group having ESS scores $\leq 11$. Interestingly, the breakpoint of the final model nearly aligns with the standard and widely-accepted cutoff on the ESS, where $\leq 10$ corresponds to non-pathological levels of daytime sleepiness and $\geq 11$ to EDS. [36]

Even though data is limited due to the small number of patients with narcolepsy included in this study, utility scores did not differ by disease status (i.e. OSA or narcolepsy) but collectively decreased as EDS 
severity increased. This suggests that sleepiness impacts utility scores, regardless of a patient's disease status. This is consistent with previous research on various health and social outcomes that show the strong effect of sleepiness irrespective of disease status.[24-30]

The strength of this study is that the model is based on data from a large number of respondents with OSA and/or narcolepsy, including a sample almost 25 times greater than the previous analytic population used to study the association between ESS scores and EQ-5D utility scores.[32] Despite the large sample in this study, only a small number of respondents with narcolepsy were included. It should be noted that the population-based nature of the NHWS survey provided epidemiologically consistent patients counts, as the literature has documented the lower prevalence of narcolepsy compared to OSA.[2, 10]

There is a potential for selection bias in this sample, as the online nature of the NHWS meant that individuals with limited or lack of internet access were less likely to participate, which could limit generalizability, especially with regards to the elderly population. However, the NHWS panel administrators attempted to have the panel mirror the population as closely as possible by controlling for age and gender during sampling. Furthermore, self-reported data is subject to recall bias, selfpresentation bias and respondent fatigue. However, self-presentation and recall bias were kept to a minimum by using validated self-reported survey measures designed to eliminate these issues (e.g., the EQ-5D is based on respondents' health 'today'). Respondent fatigue was kept to a minimum by limiting NHWS respondents to taking no more than 12 surveys per year.

Another limitation of self-reported data is that the respondent-entered data cannot be validated. Nevertheless, the self-reported nature of the data utilized in this study possesses the advantage of being both uniformly collected across the five European countries, as well as intentionally representative of the age and gender composition of the general adult population in each country.

Given the cross-sectional nature of the data, statements of causality cannot be made from the study results. Another limitation is that measured variables were accounted for in the regression, yet there is the possibility of groups differing on unmeasured variables that may have an impact on outcomes. Future research could look to address this through other statistical methods, such as propensity score matching, in order to further understand the association between ESS scores and EQ-5D utility scores.

Finally, we did not examine an alternative linear spline regression model using segments that correspond to the established intervals of non-pathological levels of EDS (ESS score 0-10) and pathological EDS (ESS score 11-24), despite the proximity of our final model results to this breakpoint. While it is possible that such a model would indicate adequate fit, the segments used to develop the final equation were based on where the best breakpoint(s) existed for the given data and were confirmed with the validation analyses.

\section{Conclusions}


The results from this large, representative, population-based study across 5 European countries provide insight into the impact of sleepiness on HRQoL. Specifically, EQ-5D utility scores decrease more significantly among those with EDS relative to those with non-pathological levels of sleepiness. These results emphasize the importance of treating and effectively managing patients' EDS associated with OSA and/or narcolepsy, as a return to a non-pathological level of sleepiness through successful treatment has the potential for significant improvements in QoL.

\section{Abbreviations}

\begin{tabular}{ll} 
AIC & Akaike Information Criterion \\
\hline BIC & Bayesian Information Criterion \\
\hline BMI & Body Mass Index \\
\hline CCI & Charlson Comorbidity Index \\
\hline CPAP & Continuous Positive Airway Pressure \\
\hline EDS & Excessive Daytime Sleepiness \\
\hline ESS & Epworth Sleepiness Scale \\
\hline GLM & Generalized Linear Model \\
\hline HRQoL & Health-related Quality of Life \\
\hline IRB & Institutional Review Board \\
\hline NHWS & National Health and Wellness Survey \\
\hline NICE & National Institute for Health and Clinical Excellence \\
\hline OSA & Obstructive Sleep Apnoea \\
\hline QoL & Quality of Life \\
\hline RMSE & Root Mean Square Error \\
\hline RoW & Rest of world \\
\hline SD & Standard deviation \\
\hline UK & United Kingdom \\
\hline US & United States \\
\hline
\end{tabular}

\section{Declarations}

\section{Ethics approval and consent to participate}


The protocol and questionnaire for the 2016 and 2017 NHWS were reviewed and granted exemption by the Pearl Institutional Review Board (IRB) as it was determined this study met the exemption requirements under 45CFR46.101(b)(2). All respondents provided informed consent.

\section{Consent for Publication}

Not applicable

\section{Availability of data and materials}

The data that support the findings of this study are available from Cerner Enviza but restrictions apply to the availability of these data, which were used under license for the current study, and so are not publicly available. Data can be made available for non-commercial use from the authors upon reasonable request and with permission of Cerner Enviza.

\section{Competing interests}

MJCM and VL are employees of Cerner Enviza, which received funding from Jazz Pharmaceuticals for study conduct and manuscript preparation. At the time of study conduct, JCR was an employee of Kantar Health, now Cerner Enviza, which received funding from Jazz Pharmaceuticals for study conduct and manuscript preparation. SM is an employee of Jazz Pharmaceuticals who, in the course of their employment, have received stock options exercisable for, and other stock awards of, ordinary shares of Jazz Pharmaceuticals plc. At the time of study conduct, JPCC was an employee of Jazz Pharmaceuticals who, in the course of their employment, received stock options exercisable for, and other stock awards of, ordinary shares of Jazz Pharmaceuticals plc.

\section{Funding}

This study was supported by Jazz Pharmaceuticals

\section{Authors' contributions}

MJCM contributed to the concept and design, analysis and interpretation of data, drafting of the manuscript, and supervision. SM contributed to concept and design, analysis and interpretation of data, critical review of the manuscript for intellectual content, obtaining funding, and supervision. VL contributed to concept and design, analysis and interpretation of data, critical review of the manuscript for intellectual content, and statistical analysis. JCR contributed to analysis and interpretation of data, drafting of the manuscript, critical review of the manuscript for intellectual content, and statistical analysis. JPCC contributed to data acquisition, drafting and critical review of the manuscript for intellectual content, and supervision. All authors read and approved the final manuscript.

\section{Acknowledgements}


Under the direction of the authors, Catherine Mason, PhD of Cerner Enviza and Hannah Ritchie, PhD and Christopher Jaworski of Peloton Advantage, LLC, an OPEN Health company, provided medical writing and editorial support for this manuscript, which was funded by Jazz Pharmaceuticals.

\section{References}

1. Mahmood M, Kushida CA. Excessive daytime sleepiness. Handb Clin Neurol. 99: Elsevier; 2011. p. 825-31.

2. Ohayon MM. From wakefulness to excessive sleepiness: what we know and still need to know. Sleep Med Rev. 2008;12(2):129-41.

3. Guilleminault C, Brooks SN. Excessive daytime sleepiness: a challenge for the practising neurologist. Brain. 2001;124(8):1482-91.

4. McWhirter D, Bae C, Budur K. The assessment, diagnosis, and treatment of excessive sleepiness: practical considerations for the psychiatrist. Psychiatry (Edgmont). 2007;4(9):26-35.

5. Khan Z, Trotti LM. Central disorders of hypersomnolence. Chest. 2015;148(1):262-73.

6. American Academy of Sleep Medicine. International classification of sleep disorders. 3rd ed: Darien,IL: American Academy of Sleep Medicine; 2014.

7. Zachariev Z, Djurkova A. Clinico-polysomnographic diagnostics of narcolepsy-cataplexy. Folia Medica. 1999;41(2):5-12.

8. Rosenthal LD, Merlotti L, Young DK, Zorick FJ, Wittig RM, Roehrs TA, et al. Subjective and polysomnographic characteristics of patients diagnosed with narcolepsy. Gen Hosp Psychiatry. 1990;12(3):191-7.

9. Punjabi NM. The epidemiology of adult obstructive sleep apnea. Proc Am Thorac Soc. 2008;5(2):136-43.

10. Benjafield AV, Ayas NT, Eastwood PR, Heinzer R, Ip MS, Morrell MJ, et al. Estimation of the global prevalence and burden of obstructive sleep apnoea: a literature-based analysis. Lancet Respir Med. 2019;7(8):687-98.

11. Hrubos-strøm H, Randby A, Namtvedt SK, Kristiansen HA, Einvik G, Benth J, et al. A Norwegian population-based study on the risk and prevalence of obstructive sleep apnea The Akershus Sleep Apnea Project (ASAP). J Sleep Res. 2011;20(1pt2):162-70.

12. Durán J, Esnaola S, Rubio R, Iztueta Á. Obstructive sleep apnea-hypopnea and related clinical features in a population-based sample of subjects aged 30 to $70 \mathrm{yr}$. Am J Respir Crit Care Med. 2001;163(3):685-9.

13. Pływaczewski R, Bednarek M, Jonczak L, Zieliński J. Sleep-disordered breathing in a middle-aged and older Polish urban population. J Sleep Res. 2008;17(1):73-81.

14. Arnardottir ES, Bjornsdottir E, Olafsdottir KA, Benediktsdottir B, Gislason T. Obstructive sleep apnoea in the general population: highly prevalent but minimal symptoms. Eur Respir J. 2016;47(1):194202. 
15. Fietze I, Laharnar N, Obst A, Ewert R, Felix SB, Garcia C, et al. Prevalence and association analysis of obstructive sleep apnea with gender and age differences-Results of SHIP-Trend. J Sleep Res. 2019;28(5):e12770.

16. Heinzer R, Vat S, Marques-Vidal P, Marti-Soler H, Andries D, Tobback N, et al. Prevalence of sleepdisordered breathing in the general population: the HypnoLaus study. Lancet Respir Med. 2015;3(4):310-8.

17. Gasa M, Tamisier R, Launois SH, Sapene M, Martin F, Stach B, et al. Residual sleepiness in sleep apnea patients treated by continuous positive airway pressure. J Sleep Res. 2013;22(4):389-97.

18. Slater G, Steier J. Excessive daytime sleepiness in sleep disorders. J Thorac Dis. 2012;4(6):608.

19. Flores NM, Villa KF, Black J, Chervin RD, Witt EA. The humanistic and economic burden of narcolepsy. J Clin Sleep Med. 2016;12(3):401-7.

20. Kim LJ, Coelho FM, Hirotsu C, Araujo P, Bittencourt L, Tufik S, et al. Frequencies and associations of narcolepsy-related symptoms: a cross-sectional study. J Clin Sleep Med. 2015;11(12):1377-84.

21. Vignatelli L, D'Alessandro R, Mosconi P, Ferini-Strambi L, Guidolin L, De Vincentiis A, et al. Healthrelated quality of life in Italian patients with narcolepsy: the SF-36 health survey. Sleep Med. 2004;5(5):467-75.

22. Vignatelli L, Plazzi G, Peschechera F, Delaj L, D’Alessandro R. A 5-year prospective cohort study on health-related quality of life in patients with narcolepsy. Sleep Med. 2011;12(1):19-23.

23. Dauvilliers Y, Paquereau J, Bastuji H, Drouot X, Weil J-S, Viot-Blanc V. Psychological health in central hypersomnias: the French Harmony study. J Neurol Neurosurg Psychiatry. 2009;80(6):636-41.

24. Mazzotti DR, Keenan BT, Lim DC, Gottlieb DJ, Kim J, Pack Al. Symptom Subtypes of Obstructive Sleep Apnea Predict Incidence of Cardiovascular Outcomes. Am J Respir Crit Care Med. 2019;200(4):493-506.

25. Björnsdóttir E, Benediktsdóttir B, Pack Al, Arnardottir ES, Kuna ST, Gíslason T, et al. The prevalence of depression among untreated obstructive sleep apnea patients using a standardized psychiatric interview. J Clin Sleep Med. 2016;12(1):105-12.

26. Ronksley PE, Hemmelgarn BR, Heitman SJ, Hanly PJ, Faris PD, Quan H, et al. Obstructive sleep apnoea is associated with diabetes in sleepy subjects. Thorax. 2009;64(10):834-9.

27. Mulgrew A, Ryan C, Fleetham J, Cheema R, Fox N, Koehoorn M, et al. The impact of obstructive sleep apnea and daytime sleepiness on work limitation. Sleep Med. 2007;9(1):42-53.

28. Ronksley PE, Hemmelgarn BR, Heitman SJ, Ward FW, Ghali WA, Manns B, et al. Excessive daytime sleepiness is associated with increased health care utilization among patients referred for assessment of OSA. Sleep. 2011;34(3):363-70.

29. Isidoro SI, Salvaggio A, Bue AL, Romano S, Marrone O, Insalaco G. Quality of life in patients at first time visit for sleep disorders of breathing at a sleep centre. Health and Quality of Life Outcomes. 2013;11(1):207. 
30. Silva GE, An M-W, Goodwin JL, Shahar E, Redline S, Resnick H, et al. Longitudinal evaluation of sleepdisordered breathing and sleep symptoms with change in quality of life: the Sleep Heart Health Study (SHHS). Sleep. 2009;32(8):1049-57.

31. Johns MW. A new method for measuring daytime sleepiness: the Epworth sleepiness scale. Sleep. 1991;14(6):540-5.

32. National Institute for Health and Care Excellence. Continuous positive airway pressure for the treatment of obstructive sleep apnoea/hypopnoea syndrome: Technology appraisal guidance [TA139] 2008 [Available from: https://www.nice.org.uk/guidance/ta139.

33. McDaid C, Griffin S, Weatherly H, Duree K, Van der Burgt M, Van Hout S, et al. Continuous positive airway pressure devices for the treatment of obstructive sleep apnoea-hypopnoea syndrome: a systematic review and economic analysis. Health Technol Assess. 2009;13(4).

34. Donovan LM, Kapur VK. Prevalence and characteristics of central compared to obstructive sleep apnea: analyses from the Sleep Heart Health Study Cohort. Sleep. 2016;39(7):1353-9.

35. Stepnowsky C, Sarmiento KF, Bujanover S, Villa KF, Li VW, Flores NM. Comorbidities, health-related quality of life, and work productivity among people with obstructive sleep apnea with excessive sleepiness: findings from the 2016 US National Health and Wellness Survey. J Clin Sleep Med. 2019;15(2):235-43.

36. Johns M, Hocking B. Daytime sleepiness and sleep habits of Australian workers. Sleep. 1997;20(10):844-7.

37. Johns MW. The Epworth Sleepiness Scale 2020 [Available from: https://epworthsleepinessscale.com/about-the-ess/.

38. British Lung Foundation. Epworth Sleepiness Scale 2019 [Available from: https://www.blf.org.uk/support-for-you/obstructive-sleep-apnoea-osa/diagnosis/epworth-sleepinessscale.

39. National Institute for Health and Care Excellence. How should I assess a person with suspected obstructive sleep apnoea syndrome? 2015 [Available from:

https://cks.nice.org.uk/topics/obstructive-sleep-apnoea-syndrome/diagnosis/assessment/.

40. EuroQol Research Foundation. EQ-5D-5L | About 2021 [Available from: https://euroqol.org/eq-5dinstruments/eq-5d-5l-about/.

41. Van Hout B, Janssen M, Feng Y-S, Kohlmann T, Busschbach J, Golicki D, et al. Interim scoring for the EQ-5D-5L: mapping the EQ-5D-5L to EQ-5D-3L value sets. Value Health. 2012;15(5):708-15.

\section{Supplementary Files}

This is a list of supplementary files associated with this preprint. Click to download.

- NHWSUtilityModellingMettamSUPPMATERIAL.pdf 